\title{
Análise dos gêneros discursivos e da enunciação aforizante no discurso de autoajuda para adolescentes
}

\section{Discursive genres and aphorizing enunciation analysis in self-help discourse for teenagers}

\author{
Marília Molina Furlan
}

\begin{abstract}
RESUMO: O objetivo deste artigo é caracterizar as ocorrências de gêneros discursivos e de enunciados aforizados no discurso de autoajuda para adolescente e seus efeitos de sentido na caracterização da cenografia e do ethos discursivo na obra selecionada para análise (IACOCCA; IACOCCA, 2008). O aparato teórico-metodológico inclui as reflexões de Maingueneau (2008a, 2008b, 2008c, 2010) sobre ethos, cenas de enunciação e enunciação aforizante e as de Brunelli (2011) sobre a enunciação aforizante no discurso de autoajuda. Considerou-se que a enunciação aforizante no discurso de autoajuda para adolescentes contribuiu para a atenuação do tom autoritário de enunciados de valor deôntico e para um tom mais informativo ao discurso. Tal constatação reforça a caracterização da cenografia instaurada pelo discurso, a de um almanaque juvenil, construída pelos diversos gêneros discursivos presentes na obra, em que o enunciador, embora apresente um status diferenciado de saber, não impõe ordens e orientações, mas apresenta fatos, informando seus enunciatários sem guiar-Ihes diretamente em suas condutas, tal como ocorre nas revistas juvenis.
\end{abstract}

PALAVRAS-ChAVE: Aforização. Autoajuda. Adolescentes. Cenografia. Ethos.

ABSTRACT: The objective of this paper is to characterize the instances of discursive genres and aphorizations in self-help discourse for teenagers and their sense effects in the scenography and the discursive ethos in the work selected (IACOCCA, IACOCCA, 2008) for analysis. The theoretical and methodological apparatus includes reflections of Maingueneau (2008a, 2008b, 2008c, 2010) on ethos, on enunciation scenes, on aphorizations and Brunelli's reflections (2011) on aphorization in the self-help discourse. It was considered that the aphorizing utterance in the self-help discourse for teenagers contributed to the attenuation of the authoritative tone of statements with deontic value and a more informative tone to the discourse. This finding reinforces the characterization of scenography introduced by discourse, a youth almanac, built by

\footnotetext{
$1^{*}$ Doutoranda (bolsista Capes) do Programa de Pós-Graduação em Estudos Linguísticos da Universidade Estadual Paulista "Júlio de Mesquita Filho", campus de São José do Rio Preto, desde 2014. Mestra em Estudos Linguísticos, área de Análise Linguística, pela mesma Universidade, desde 2013. Graduada em Licenciatura em Letras pelo Instituto de Biociências, Letras e Ciências Exatas (UNESP/IBILCE) desde 2010. Contato: mariliamolinafurlan@yahoo.com.br.
} 
several discursive genres present in the work, in which the enunciator, although having a different status to know, does not impose orders and guidelines, but presents facts, informing their audience without guiding them directly into their behaviours, as it occurs in youth magazines.

KEYWORDS: Aphorization. Self-help. Teenagers. Scenography. Ethos.

\section{O discurso de autoajuda}

Estudos de vários campos científicos, dentre eles o das Ciências Sociais, o da Educação e o da Análise do Discurso (RÜDIGER, 1996; MARÍN-DÍAZ, 2015; BRUNELLI, 2004, respectivamente), têm-se direcionado a explicar o funcionamento do discurso veiculado nas obras de autoajuda, seja pela descrição específica de aspectos sociológicos e históricos que condicionaram sua constituição, seja pela análise dos mecanismos enunciativos que 0 particularizam.

A escolha deste objeto de estudo considera principalmente a relevância da ideologia individualista para o discurso de autoajuda e os números do mercado editorial em relação às publicações e às vendas dessas obras. As vendas de obras de autoajuda ganham destaque pela parcela cada vez maior no mercado editorial brasileiro, embora este crescimento não seja um fenômeno exclusivamente nacional. Segundo dados de artigo de Marthe (2002) publicado pela revista Veja, as vendas dessas obras no Brasil entre os anos finais da década de 90 e início dos anos 2000 aumentaram em 700\%. Nos Estados Unidos, segundo a mesma publicação, em 2001 foram lançados, aproximadamente, 3500 títulos e as editoras faturaram mais de 600 milhões de dólares nas vendas desse setor.

O sucesso mercadológico das obras de autoajuda pode ser considerado uma amostra do potencial que o discurso de autoajuda tem para promover, no contexto sócio-histórico contemporâneo, a ideologia centrada no individualismo pós-moderno que define as atuais sociedades. Em geral, o individualismo é caracterizado nos trabalhos que se dedicam ao tema (BAUMAN, 1998; CHAGAS, 
2001; RÜDIGER, 1996) como um fenômeno ideológico em que os deslocamentos nos referenciais de identificação (de coletivos para individuais) e pela exigência de novos estilos de vida, que levam a construções e reconstruções de identidades que sirvam ao modelo capitalista vigente. Nesse contexto, o sujeito pós-moderno, embora seja um indivíduo que se vê livre para tomar decisões, encontra-se solitário e dependente de si mesmo, desprovido de um lugar social bem definido. Além disso, tende a pôr em evidência a si mesmo em detrimento das forças sociais que o constituem, que o mobilizam e que 0 integram em determinada coletividade. $O$ indivíduo pós-moderno se encontra impelido a tentar diminuir suas fragilidades e superar as dificuldades pessoais em busca do bem-estar e da satisfação pessoal. Por isso, o individualismo pósmoderno também se caracteriza pela incessante necessidade de satisfação de desejos particulares originados pelas novas relações de consumo características do capitalismo.

O enfoque na resolução dos problemas individuais e na constituição de uma personalidade nos moldes capitalistas, que é determinada, em grande medida, a suprir primordialmente necessidades particulares e é, por vezes, indiferente às condições sócio-históricas que acarretam os problemas de ordem social que afetam as sociedades modernas, parece alavancar as vendas das obras de autoajuda. Assim, tais obras investem na promoção de um indivíduo ideal característico da contemporaneidade: seguro, autoconfiante, determinado e concentrado em alcançar sucesso profissional e financeiro.

Neste artigo, pretende-se contribuir com os estudos sobre o discurso de autoajuda, analisando um livro de autoajuda destinado ao público adolescente ${ }^{2}$, uma de suas vertentes mais recentes e uma das menos pesquisadas. Dados do Levantamento Anual do Segmento de Livrarias, realizado pela Associação Nacional das Livrarias em 2010, indicam que o setor de vendas de obras destinadas ao público infanto-juvenil foi o que mais cresceu no Brasil. Entre tais

\footnotetext{
2 Os resultados descritos no presente artigo inscrevem-se em análises apresentadas em dissertação de mestrado. O objetivo da pesquisa era caracterizar o ethos discursivo e as cenografias de livros de autoajuda para adolescentes (FURLAN, 2013).
} 
publicações, encontram-se obras de autoajuda para o público juvenil. Dessa forma, trata-se também de contribuir com os estudos de discursos sobre a adolescência ou voltados aos adolescentes, revelando mecanismos enunciativos que caracterizam ou especificam o modo de enunciar de produções textuais destinadas a esse público.

Para tanto, adota-se o aparato teórico-metodológico da Análise do Discurso de linha francesa ( $A D$, doravante), especialmente os trabalhos de Maingueneau (2008a, 2008b, 2008c) sobre os conceitos de cenas de enunciação e ethos. De um ponto de vista mais específico, este trabalho pretende investigar o ethos do discurso de autoajuda para adolescentes e caracterizar a(s) cena(s) de enunciação na(s) qual(is) esse ethos emerge. 0 ethos discursivo é considerado, basicamente, como a imagem relacionada ao sujeito enunciador do discurso revelado pelo próprio modo como enuncia; e o interesse pelo conceito se deve ao fato de que está diretamente ligado à questão da eficácia de um discurso, isto é, à sua capacidade de suscitar a crença. A análise do ethos vincula-se à análise da cena de enunciação instaurada na obra, uma vez que o ethos participa da constituição dessa cena, que é a que o discurso pressupõe para poder ser enunciado e que ele legitima por sua própria enunciação (MAINGUENEAU, 2008b).

Em relação à estrutura do presente trabalho, o artigo organiza-se da seguinte forma: na primeira seção descrevem-se os princípios teóricos da $A D$ que fundamentam a análise da obra considerada; na segunda seção apresentase o livro selecionado para análise e aborda-se a caracterização da cenografia da obra com base nos gêneros discursivos encontrados; na terceira seção, retoma-se o construto teórico sobre a enunciação aforizante do livro analisado e analisam-se os seus efeitos na caracterização da cenografia e do ethos discursivo das obras. Por fim, nas considerações finais do trabalho, sintetizamse os principais resultados das análises desenvolvidas. 


\section{Ethos discursivo e cenografia}

Em termos mais gerais, o conceito de ethos discursivo pode ser descrito como a imagem que o enunciador projeta de si mesmo pela forma com que enuncia. Segundo Maingueneau (2008a), o ethos é um saber inferido a partir da enunciação e não um saber extradiscursivo sobre o locutor. Assim, ao destinatário cabe a tarefa de atribuir certas características à entidade que se manifesta como origem da enunciação, considerando o modo como enuncia.

Ainda de acordo com o autor, entende-se que o ethos, assim como o locutor apreendido como enunciador, mostra-se na enunciação, sem ser dito no corpo do enunciado. Ou seja, essa imagem do enunciador é percebida no discurso, sem ser o objeto deste discurso, o que significa que o ethos não se identifica com os atributos reais do locutor, mesmo que esteja associado a ele. A esse respeito, Maingueneau (2008b) afirma que o destinatário atribui ao locutor inscrito no mundo extradiscursivo traços que são, na verdade, intradiscursivos, pois são associados a uma forma específica de dizer, de enunciar.

Maingueneau (2008b) elenca os seguintes princípios mínimos que embasam os diversos tratamentos dados a noção de ethos: (i) o de que se trata de uma noção discursiva, isto é, que ele se constrói no discurso (não é uma imagem independe da enunciação); (ii) o de que se trata de um processo interativo de influência sobre o outro; (iii) o de que se trata de uma noção híbrida (sócio-discursiva), "um comportamento socialmente avaliado, que não pode ser apreendido fora de uma situação comunicativa específica, integrada ela mesma numa determinada conjuntura sócio-histórica" (MAINGUENEAU, 2008b, p. 17).

Para o autor, a noção de ethos mantém um laço especial com a reflexividade enunciativa e permite articular corpo e discurso para além da distinção entre oral e escrito. Mais exatamente, a instância subjetiva que se manifesta no discurso se deixa conceber como uma espécie de "voz" indissociável de um corpo enunciante, que é historicamente especificado. Desse 
modo, todos os textos, mesmo os escritos, têm uma vocalidade, que pode se manifestar numa multiplicidade de tons ${ }^{3}$ associados a certa caracterização do corpo do enunciador, considerado o "fiador", isto é, o responsável pela enunciação. Esse fiador é construído pelo destinatário a partir dos índices liberados na enunciação.

Com essa perspectiva, Maingueneau (2008a) apresenta uma concepção de ethos que ele chama de "encarnada", recobrindo não só a dimensão verbal, mas também o conjunto de determinações físicas e psíquicas do "fiador". Essas determinações, por sua vez, dizem respeito a representações coletivas estereotípicas. Assim, atribui-se ao fiador certo caráter (concebido como um feixe de traços psicológicos) e certa corporalidade (uma constituição física associada a uma forma de se vestir), que juntos implicam uma forma específica de se mover no espaço social, certo comportamento associado a estereótipos sociais que a enunciação contribui para manter ou transformar e nos quais os destinatários se apoiam para sua apreensão da imagem do enunciador. Assim, entende-se que o destinatário tem um papel relevante na construção do ethos do enunciador, pois é ele que, com base nos traços intradiscursivos, relaciona o modo de dizer do enunciador a representações coletivas e culturais relativas a modos específicos de habitar o mundo, atribuindo, desse modo, ao fiador certa imagem psicológica e social.

Além dessas propriedades, o ethos está vinculado à cena de enunciação, que, segundo Maingueneau (2008a), engloba três cenas: a cena englobante, a cena genérica e a cenografia. A cena englobante corresponde ao tipo de discurso; ela confere ao discurso seu estatuto pragmático (por exemplo: discurso literário, discurso religioso, discurso filosófico, discurso publicitário). A cena genérica, por sua vez, diz respeito ao contrato associado a determinado gênero (editorial, sermão, guia turístico, visita médica, receita etc.). Finalmente, tem-se a cenografia, cena construída pelo próprio texto, que não é necessariamente imposta pelo gênero; assim, por exemplo, um sermão pode

\footnotetext{
3 Maingueneau (2008b) prefere empregar o termo "tom", pela vantagem de valer tanto para o escrito quanto para o oral.
} 
ser enunciado por meio de uma cenografia professoral. A cenografia é exatamente o lugar onde o fiador do discurso está inserido, assumindo certo modo de enunciação.

Dado o interesse nesse último tipo de cena para este trabalho, já que é nele que emerge o ethos discursivo, convém destacar outras observações de Maingueneau (2008c) a respeito da cenografia. A importância da cenografia para o discurso pode ser assim descrita por Maingueneau (2008c, p. 117):

A escolha da cenografia não é indiferente: o discurso, desenvolvendose a partir de sua cenografia, pretende convencer instituindo a cena de enunciação que o legitima. O discurso impõe sua cenografia de algum modo desde o início; mas, de outro lado, é por intermédio de sua própria enunciação que ele poderá legitimar a cenografia que ele impõe. Para isso, é necessário que ele faça seus leitores aceitarem o lugar no universo de sentido que ele instaura. (grifos do autor).

Desse modo, entende-se que, para o autor, a cenografia não se confunde com um quadro predeterminado dentro do qual uma enunciação é inserida. Trata-se de um dispositivo próprio ao discurso que se desenvolve simultaneamente à sua enunciação e que, ao mesmo tempo em que a legitima, é legitimado por ela. É a própria enunciação que especifica a cenografia e esta é a única que permite que tal enunciação funcione para determinado universo de sentido que um discurso manifesta, contribuindo, inclusive, para a aceitação, convencimento e adesão dos co-enunciadores ao discurso em questão. Dessa forma,

[...] a cenografia é, ao mesmo tempo, origem e produto do discurso; ela legitima um enunciado que, retroativamente, deve legitimá-la e estabelecer que essa cenografia de onde se origina a palavra é precisamente a cenografia requerida para contar uma história, para denunciar uma injustiça etc. Quanto mais o enunciador avança no texto, mais ele deve se persuadir de que é aquela cenografia, e nenhuma outra, que corresponde ao mundo configurado pelo discurso. (MAINGUENEAU, 2008c, p. 118, grifos do autor).

Na próxima seção, apresenta-se a obra selecionada para análise e caracteriza-se a sua cenografia considerando-se os gêneros discursivos encontrados. 


\section{Cenografia e os efeitos de sentido da combinação de gêneros discursivos}

A obra analisada neste artigo é $O$ livro do adolescente: discutindo ideias e atitudes com o jovem de hoje (IACOCCA; IACOCCA, 2008). Nesta obra, os autores discutem variados temas, desde aqueles mais próximos da vida do adolescente, como família, namoro, amizade, profissão, aparência, drogas, internet, televisão, até temas mais relacionados à preparação do adolescente para a vida adulta, como cidadania, violência, discriminação, direitos humanos, ética, meio ambiente, política e voluntariado.

Uma das primeiras características da obra analisada é o apelo a diversos gêneros discursivos na composição dos capítulos. Nesta seção, analisam-se os efeitos de sentido relativos a essa combinação de gêneros, considerando-se as suas características.

Logo no sumário ou índice da obra de Iacocca e Iacocca (2008), observa-se um distanciamento em relação às típicas obras de autoajuda. Nessas obras, os sumários apresentam tópicos sequenciais relativos às formas de autodesenvolvimento pessoal ou profissional de acordo com as propostas dos autores (SOBRAL, 2006) ${ }^{4}$. Dessa forma, a leitura de tais obras apresenta-se ao leitor como ordenada por etapas ou fases do processo de autoajuda, previamente organizadas, o que não se verifica na obra de Iacocca e Iacocca (2008).

A obra em questão está organizada por temas diversificados, apresentados em função de palavras-chave, que englobam diferentes assuntos em um mesmo tópico e que estão ordenadas única e exclusivamente pelo critério da ordem alfabética. Como exemplo, podem-se citar as palavras-chave iniciadas pela letra $p$, que reúnem ora temas mais públicos, como paz e política,

\footnotetext{
${ }^{4}$ Embora se compare, em alguns excertos da análise, diferentes propostas de textos de autoajuda (como os religiosos, pesquisados por Sobral, 2006), não se constitui como objetivo deste artigo discutir tal comparação.
} 
ora mais particulares, como profissão e primeira vez. Não há títulos, somente ocorrem as palavras-chave, o que converge para uma leitura mais dinâmica e direta. Portanto, desde a organização do sumário, observa-se uma relação entre enunciador e enunciatário que difere da encontrada, por exemplo, por Sobral (2006), em que os capítulos das obras de autoajuda espiritual analisadas pelo autor organizavam-se segundo os passos de uma "jornada" espiritual de autoconhecimento.

Essa apresentação da organização da obra parece condizer com as expectativas de um público adolescente, cuja imagem se distancia do leitor típico de autoajuda. Sem direcionar ou conduzir estritamente a leitura do livro, o enunciador projeta para si mesmo uma imagem menos autoritária, seja pela forma como os capítulos se dispõem, seja pela seleção dos títulos, de modo a dar liberdade e autonomia de leitura aos jovens, tal como ocorre, por exemplo, em revistas ou almanaques para adolescentes.

Em relação à constituição interna dos capítulos, a mesma dinamicidade que se verificou no sumário encontra-se na disposição dos enunciados e na intergenericidade que são convocados para o tratamento dos tópicos. Os capítulos reúnem, simultaneamente, boletins informativos, relatos, conversas diretamente direcionadas aos leitores, testes, listas, depoimentos, histórias em quadrinhos $^{5}$, o que confere ao discurso de autoajuda uma cenografia mais dinâmica e mais informal. Na análise a seguir, obedece-se a sequência dos gêneros tal como foram mencionados.

Tal como nos almanaques e revistas juvenis, os textos informativos (relatos e boletins informativos) são curtos e separadamente delimitados por certos recursos visuais, a saber, tamanho da fonte e enquadramento em espaços específicos no início ou no final dos capítulos. Além disso, os textos não apresentam dados relativos a um saber pessoal ou cientificamente comprovados, mas um conhecimento geral ou uma verdade universal derivada das observações cotidianas, que poderiam ser realizadas por qualquer pessoa. domínios discursivos e modalidades apresentada por Marcuschi (2008, p. 194-196). 
Assim, tais constatações, que podem ser atribuídas tanto ao enunciador quanto aos jovens, promovem também uma relação mais próxima entre eles, atenuando o traço de conhecimento especializado que se prestaria a sustentar uma hierarquia mais definida entre enunciador e enunciatário.

Os enunciados de textos pertencentes ao gênero conversacional (conversações), que mostram claramente uma relação interlocutiva entre enunciador com o público-alvo, trazem sugestões, apresentadas especialmente por meio de interrogações, nas quais o enunciador tenta conduzir as atitudes e comportamentos dos adolescentes em determinadas direções, propósito esse que aproxima tal obra do gênero autoajuda, ainda que essa orientação se dê de forma mais atenuada e diluída.

Essas interrogações, que indiretamente propõem reflexões e mudanças de comportamentos aos adolescentes, também colaboram na construção de uma cenografia de diálogo, de interlocução direta entre os participantes, que não se limita, portanto, a uma mera exposição de dicas, passos e formas para se alcançarem certas metas.

Não se trata, nessas "instruções", de instaurar uma relação enunciativa que intimide o enunciatário, pois, no lugar da voz onipotente de um especialista que o guia autoritariamente, o adolescente se depara com o que é, supostamente, a sua própria voz, com as suas próprias emoções e pensamentos, que aparecem listados nessas interrogações. Emerge, assim, a imagem de um enunciador próximo: é respeitoso com o público, com os seus sentimentos e com os seus pensamentos e parece estar interessado no diálogo, cedendo espaço para a voz do próprio adolescente.

Além disso, ao enumerar, nas interrogações, diversos tipos de comportamento ou de sensações que os adolescentes já podem ter experimentado, o sujeito enunciador demonstra conhecer o público ao qual se dirige. Assim, há condições para o adolescente se identificar com os tipos de comportamentos listados nos enunciados interrogativos que se assemelham muito aos testes dos almanaques juvenis. Diga-se o mesmo a respeito das listas, que enumeram tipos de comportamentos, emoções e situações que 
exemplificam modos de vivenciar a adolescência e dos depoimentos que apresenta.

Ao mesmo tempo em que esses testes não limitam os tipos de atitudes dos jovens, há uma abertura para novas possibilidades de condutas que se enquadrem em determinado tema. A orientação, por parte do enunciador, torna-se, desse modo, diluída em função do papel de entretenimento normalmente associado aos testes. Com isso, o tom autoritário da autoajuda tradicional é substituído por um tom mais sugestivo, em especial nos enunciados iniciados pela expressão interrogativa que tal, recorrente na obra. Nesses termos, entende-se que o enunciador mostra-se interessado no que os próprios adolescentes sentem e pensam.

Como ilustração das interrogações referentes às sugestões de tipos de comportamento, observem-se os exemplos de (01) a (03):

(01) Você é do tipo que... não está nem aí para a própria aparência? adora se exibir? deseja andar na moda a qualquer custo? consegue cuidar da aparência com pouco dinheiro? acha que o sucesso de uma pessoa depende da grife que ela usa? procura através da aparência mostrar exatamente quem você é? vive se comparando aos ídolos que aparecem nas de revistas e na TV? (IACOCCA; IACOCCA, 2008, p.11).

(02) Como anda sua autoestima? Está satisfeito em ser como é? Vive querendo ser diferente do que é? Consegue reconhecer suas qualidades e dificuldades? Pensa sempre de forma negativa a seu respeito? (IACOCCA; IACOCCA, 2008, p.12).

(03) O que você acha que vai ganhar se... deixar a timidez de lado e expor suas opiniões? der férias para a preguiça? perceber que você não é culpado de tudo o que acontece, pois não está sozinho no mundo? apostar no otimismo? mostrar interesse pelo que ocorre ao seu redor? controlar aquele medo bobo que só atrapalha? contar até dez antes de estourar? gostar mais de si mesmo e adquirir confiança? (IACOCCA; IACOCCA, 2008, p.21).

No que diz respeito às listas de comportamentos apresentados, observase que expressam valores dicotômicos. Se o jovem identifica-se, por exemplo, com alguém que separa o lixo para ser reciclado, esse comportamento está associado a um valor positivo, mas, por outro lado, ele pode se identificar com alguém que não guarda os segredos de uma amiga (valor negativo). Assim, há 
uma sugestão, por meio das listas, do que é correto fazer ou não, sem comprometer diretamente o enunciador com essas orientações, pois caberia ao enunciatário, por si mesmo, identificar os bons e maus comportamentos entre aqueles que são listados. Trata-se de mais um recurso que dilui o tom autoritário dos enunciados que se prestam a orientar aos jovens. Como exemplos, seguem-se os enunciados de (04) a (08):

(04) Tem o jovem cheio de certezas e o confuso, o que acha que sabe tudo, o que acha que não sabe nada, o que quer mudar o mundo e o que não está nem aí, o bem-humorado e o mal-humorado, o pacífico e o agressivo, o controlado e o impulsivo, o que tem dinheiro para gastar e o que não tem, o considerado bonito e o considerado feio, 0 ligado e o desligado... (IACOCCA; IACOCCA, 2008, p.76).

(05) Pequenas atitudes que ajudam a preservar o meio ambiente. Separar o lixo par ser reciclado. Manter o automóvel em bom estado para não soltar fumaça preta (monóxido de carbono). Estar atento para não comprar produtos de fabricantes que destroem e poluem 0 meio ambiente. Dar preferência aos produtos feitos com material reciclado. Participar de campanhas, associações de bairro que preservam a limpeza das ruas, a conservação das praças, das áreas verdes. Economizar água e energia elétrica. Ajudar a preservar todos os espaços da sua escola. Dizer não à pichação. (IACOCCA; IACOCCA, 2008, p.93).

(06) Qual destas pessoas se comporta com mais agressividade? A nervosa que vive estourando e quer bater em todo mundo. A metida a engraçadinha que dá risadinhas, faz pouco caso e conta piadinhas preconceituosas contra os outros. A arrogante que invade o espaço alheio. A impulsiva que ofende com palavras pesadas. (IACOCCA; IACOCCA, 2008, p.15).

(07) Você age assim... Espalha na turma um segredo que a amiga pediu que guardasse. É gentil. Grita, xinga e bate portas quando é contrariado. Aceita críticas sobre suas atitudes. Fala 'bom dia, boa tarde, dá licença, me desculpe, muito obrigado'. Aponta mais defeitos que as qualidades dos outros. Provoca, provoca...até as pessoas perderem a paciência. (IACOCCA; IACOCCA, 2008, p.31).

(08) Alguns exercícios cotidianos de cidadania. A defesa do meio ambiente. O comportamento civilizado no trânsito. A busca de informação. $O$ combate à discriminação. $O$ voluntariado. $O$ respeito à liberdade de pensamento e de ação do outro. A não-violência. $O$ cultivo da tolerância. A não-aceitação das injustiças sociais. (IACOCCA; IACOCCA, 2008, p. 33).

Com relação aos depoimentos, são gêneros comumente presentes em 
almanaques juvenis e o seu emprego certamente colabora para que o públicoleitor possa se identificar com as situações citadas. Como ilustração desses depoimentos, seguem-se as ocorrências (09) a (12):

(09) Esta é a opinião de Leandra, 14 anos, sobre a amizade: 'Acho que viver sem amigos é praticamente impossível. É com eles que eu me entendo, que converso do jeito que gosto de conversar, que me divirto... De vez em quando acontece uma discussão, uma briguinha, mas depois tudo volta ao normal... acho que isso faz parte! (IACOCCA; IACOCCA, 2008, p.16).

(10) O que você pensa das bebidas alcoólicas? 'Bem, acho que é uma coisa complicada. Tem muita gente que sai bebendo e acaba fazendo besteira. Não acho graça nenhuma em quem cai na bebedeira e fica todo zoado arrumando briga e acidentes. (Igor- 15 anos) (IACOCCA; IACOCCA, 2008, p.23).

(11) Eu gosto da escola em que estudo agora. Deixam a gente bem à vontade, os alunos podem dar opiniões e participar, alguns professores são mais compreensivos e outros, mais, mais, nem sei... $\mathrm{E}$ é na escola que eu encontro meus amigos.' (Isa-14 anos) (IACOCCA; IACOCCA, 2008, p.52).

(12) Cícero, 16 anos, e a Internet: 'Se pudesse, eu passaria dia e noite navegando. Só saio da rede quando alguém em casa quer usar o telefone. Meus pais reclamam.... vivem dizendo que meu caso já virou doença.... O que sei é que não vejo a hora das aulas serem online.' (IACOCCA; IACOCCA, 2008, p. 74).

Ainda no que concerne aos depoimentos, na obra em análise, eles estão sempre destacados, assim como é feito nos almanaques e nas revistas juvenis. Antes de citar a voz dos jovens, por meio do discurso relatado em estilo direto, o enunciador do discurso de autoajuda não faz nenhum tipo de comentário introdutório, o que se pode interpretar como uma forma de respeitar a palavra do adolescente, dada a distância, isto é, a ausência de um contato mais direto entre as vozes. Com esse afastamento, o depoimento pode ser percebido como a voz do adolescente, daquele ser que merece um espaço próprio para manifestar-se e dizer o que sente, o que experiencia e o que pensa.

$\mathrm{Na}$ organização dos capítulos que apresentam tais depoimentos, a maioria de suas ocorrências finaliza as discussões de um determinado tópico, indicando que é o adolescente que dá a palavra final. Esse procedimento, além de valorizar a palavra do adolescente, também indica que o sujeito enunciador 
concorda com o seu ponto de vista, o que os aproxima e confere uma imagem positiva ao sujeito enunciador.

Outras vezes, inclusive, o desenvolvimento de um tópico está todo baseado nos depoimentos, o que indica que o enunciador se vale do próprio dizer dos adolescentes para validar um posicionamento sobre determinado tópico, funcionando como mais um tipo de recurso enunciativo que os aproxima. Tal expediente de uso de depoimentos é altamente recorrente nas revistas adolescentes, cuja comercialização está estritamente vinculada a este estreitamento de laços de identificação entre os enunciadores dos textos ao enunciatário adolescente.

Assim, a tal enunciatário associa-se uma imagem de descontração, de proximidade, de informalidade, de sociabilidade que faz com que quem a eles se dirija procure estabelecer com eles uma relação mais simétrica e menos impositiva, respeitando o espaço e a autonomia que almejam alcançar.

Cabe ressaltar que o traço de humor, de diversão e de entusiasmo que o senso comum atribui aos adolescentes manifesta-se na obra em análise por meio da recorrência às histórias em quadrinhos, gênero comumente associado a esse público.

$\mathrm{Na}$ obra, tais histórias contêm sempre um tom de irreverência e, ao iniciarem os capítulos, funcionam como um recurso para desarmar o público alvo de possíveis objeções ao texto, principalmente, quando os temas estão vinculados aos cenários da vida cotidiana considerados mais "sérios", tais como alcoolismo, cidadania, consumo, discriminação etc. Não se trata, no entanto, de histórias com tom crítico ou sarcástico, mas de histórias cujos enredos provocam riso pelas situações de desencontros entre os posicionamentos dos personagens (os adolescentes) ou pela sua desorientação em relação aos temas tratados em cada capítulo. Desta maneira, tais situações projetam a seguinte imagem da adolescência: etapa da vida humana marcada por confusões, desencontros, dúvidas e questionamentos sobre os tipos de comportamentos adequados ou não para o ingresso na vida adulta.

Nesses termos, entende-se que o adolescente é retratado como um ser 
envolvido em pequenos dilemas cotidianos que serão esclarecidos no desenvolvimento dos capítulos, os quais introduzem os temas correspondentes, por meio de uma abordagem didática e elucidativa, e não autoritária.

Por fim, quanto à disposição dos gêneros apresentados na composição dos capítulos, convém observar que as histórias em quadrinhos funcionam como "porta de entrada" para o tema em questão, já sinalizando, pelos diálogos estabelecidos, certa orientação de tratamento desse tema, com um tom de humor típico dos almanaques juvenis de entretenimento.

Na sequência da composição dos capítulos, encontram-se, em um espaço gráfico delimitado, relatos e boletins informativos que funcionam como introdução do tema pela voz do enunciador. Tais textos são muito curtos e não ultrapassam, em geral, dez linhas, contribuindo para uma enunciação mais direta. Esses são os gêneros que introduzem os capítulos.

Posteriormente, seguem as listas, testes, depoimentos, delimitados também em espaços gráficos próprios, que podem estar entremeados ou não por novas ilustrações e histórias em quadrinhos. Na finalização dos capítulos encontram-se novos depoimentos, resumos do que foi dito e instruções de como pensar ou agir em relação ao tema proposto, orientações estas que também se encontram na autoajuda para adultos (SOBRAL, 2006; BRUNELLI, 2004). Constata-se, assim, uma dinamicidade promovida pela alternância de gêneros, característica que não raramente é associada ao adolescente, visto como um indivíduo irrequieto e extremamente ativo.

Os jogos de cores entre as seções dos capítulos (preto, branco e verde) também destacam partes do texto, agregando mais dinamicidade à leitura de cada parte, conforme há um efeito visual diferente para cada gênero utilizado. As seções (cada uma relativa a certo gênero) também são formatadas em diferentes fontes, em diferentes enquadramentos, o que reforça, mais uma vez, a independência da cada seção.

Diante do exposto, pode-se dizer que a obra em análise, embora comercializada como pertencente à categoria de autoajuda, organiza e projeta em sua enunciação traços de outros gêneros discursivos, mais especificamente 
a de um almanaque ou revista juvenil. Dessa forma, observa-se uma cenografia que se distancia da cena enunciativa típica de autoajuda, na qual o enunciador, assumindo um lugar de saber, se coloca num lugar hierarquicamente superior ao enunciatário, ditando-Ihe autoritariamente o comportamento correto.

Em outras palavras, diferentemente do processo de parasitismo do gênero de autoajuda psico-cósmica analisada por Sobral (2006), em que a interação de outros gêneros visa a reforçar o estatuto de saber diferenciado dos sujeitos enunciadores em relação ao público leitor e a autoridade que Ihes é conferida em função desse saber, na obra em análise a interação dos gêneros visa a amenizar a distância entre enunciador e público constitutiva do discurso de autoajuda tanto da vertente psico-cósmica quanto da vertente empresarial, analisada por Brunelli (2004). Portanto, na obra em questão, com a cenografia do almanaque juvenil, atenua-se essa relação assimétrica entre os participantes da enunciação, o que dilui o tom autoritário típico do discurso de autoajuda.

No próximo item, analisa-se a presença de enunciados destacados sob o regime de enunciação aforizante e seus efeitos de sentido.

\section{Enunciação aforizante}

Analisando fórmulas, isto é, enunciados curtos, dotados de certas propriedades que facilitam a sua memorização, Maingueneau (2010) nota que muitos desses enunciados foram extraídos, quer dizer, destacados de textos, 0 que leva o autor a chamá-los de enunciados destacados.

Esses enunciados pertencem a duas classes distintas, conforme o destacamento do enunciado seja constitutivo ou por extração. Entre os casos de destacamento constitutivo, estão os provérbios e todas as fórmulas sentenciosas que não são dotadas de um contexto situacional nem de cotexto original. No outro grupo, encontram-se os fragmentos extraídos de um texto específico. Segundo Maingueneau (2010), essa extração não acontece de maneira aleatória, pois alguns fragmentos têm propriedades (por exemplo, uma forte relação com a temática do texto, o fato de ser enunciado generalizante, 
etc.) que favorecem sua extração.

Conforme nota Maingueneau (2010), os enunciados destacados têm um status pragmático especial, isto é, eles decorrem de um regime de enunciação específico, a que o autor chama de enunciação aforizante, em oposição à enunciação textualizante.

$\mathrm{Na}$ enunciação textualizante, cada gênero do discurso atribui papéis específicos aos sujeitos envolvidos em sua produção e recepção. No entanto, na enunciação aforizante, há somente uma dessas instâncias que se dirige a uma espécie de público universal, ou seja, a enunciação não está orientada a um destinatário ou a um grupo de destinatários particular. Não há, portanto, a presença de duas figuras enunciativas, pois a enunciação aforizante tem, nas palavras do autor, "como efeito, centrar a enunciação no locutor" (MAINGUENEAU, 2010, p. 13).

Na enunciação textualizante, os pensamentos estão articulados por meio de jogos de linguagem de diversas ordens, tais como argumentar, narrar, responder. A enunciação aforizante, por sua vez, não se insere em qualquer jogo de linguagem, exprimindo apenas o pensamento do locutor, aquém de qualquer jogo de linguagem.

No que diz respeito aos planos enunciativos presentes em cada tipo de enunciação, o autor ressalta que, enquanto diferentes figuras do enunciador, diferentes status polifônicos, diferentes planos textuais estão imbricados na enunciação textualizante, há uma perda dessa heterogeneidade enunciativa na enunciação aforizante, ou seja, os planos enunciativos aí se tornam homogêneos.

Outra diferença diz respeito às formas de subjetividade: se um texto implica diferentes subjetividades vinculadas a suportes e modos de circulação, o mesmo não ocorre com as aforizações, já que essa forma de enunciação, para o autor, "é uma forma de dizer puro, quase próxima de uma consciência" (MAINGUENEAU, 2010, p.14).

Quanto à relação com a dimensão extra-verbal, os tipos de enunciação também contrastam: na enunciação textualizante, a produção verbal é um 
dentre outros elementos da comunicação verbal, mas as aforizações pretendem-se ser puras, excluindo-se dos outros elementos do quadro de enunciação, tais como imagens, gestualidade, entonações, etc.

Além disso, ainda que as enunciações textualizantes não sejam passíveis de memorização, as aforizações o são, implicando uma constante possibilidade de atualização, ou seja, elas formam, segundo o autor, "uma fala viva sempre disponível [...] como parte de uma repetição constitutiva" (MAINGUENEAU, 2010, p. 14).

Tendo em vista as características citadas, Maingueneau (2010) afirma que a enunciação aforizante implica um ethos específico, isto é, o ethos do sujeito que está no alto, do indivíduo autorizado, que está em contato com uma fonte transcendente. Esse sujeito, ainda nas palavras de Maingueneau (2010, p. 15), é aquele que:

\begin{abstract}
se coloca como responsável, afirma valores e princípios perante o mundo, dirige-se a uma comunidade que está além dos alocutários empíricos que são seus destinatários. Na tradição filosófica, o Sujeito, o sub-jectum, está situado abaixo, ele é o que não varia, o que escapa à relatividade dos contextos; Sujeito pleno, o aforizador pode responder por aquilo que diz através da pluralidade de situações de comunicação.
\end{abstract}

Maingueneau (2010) também nota que a descontextualização das aforizações pressupõe uma opacificação de seu sentido, que exige um trabalho interpretativo, no qual dizendo $X$, o locutor implica $Y$, onde $Y$ pode ser um enunciado genérico de valor deôntico (MAINGUENEAU, 2010, p.15). Assim, o conteúdo do enunciado deve ser entendido como uma verdade, que prescinde de negociação.

Brunelli (2011, p. 131) observa que a ocorrência de enunciados aforizados é comum em obras de autoajuda, o que também se constata numa das obras do corpus. Ao analisar enunciados aforizados em livros de autoajuda voltados à temática profissional e de negócios, a autora nota que tais enunciados são dotados de traços que thes conferem uma grande independência de contextos, o que lhes permite, aparentemente, a inserção em 
outros contextos sem prejuízo ou alteração de sentido. Quanto a esses enunciados, a autora afirma:

a) trata-se de enunciados impessoais, e os eventuais pronomes empregados são termos referencialmente vazios, ou ainda, são pronomes de percurso que não permitem a identificação de um único objeto, mas levam o interlocutor a percorrer todos os indivíduos a que ele possa se referir;

b) em função da sua impessoalidade, podem passar da impessoalidade à pessoalidade e vice-versa;

c) não apresentam dêiticos, sejam eles espaciais ou temporais e tampouco alguma referência definida; as suas referências "dizem respeito a classes ou a indivíduos que as representam, e não a um único referente específico ligado à situação de comunicação".

Com essas características, a autora conclui que se trata de enunciados genéricos que levam o interlocutor a uma inferência que contenha um universal (como sempre, jamais, todo, tudo, nenhum, ninguém, etc.). A esse respeito, afirma:

[...] nesses enunciados, a ausência de valor referencial específico para os seres mencionados é fundamental, pois nunca se trata de especificidade, mas de universalidade. Isso também é válido para os enunciados destacados metafóricos, cujas expressões, ao constituírem uma metáfora, perdem seu sentido próprio e específico, levando à inferência de uma verdade universal, expressa no presente genérico. (BRUNELLI, 2011, p. 131-132).

Segundo Brunelli (2011), esses enunciados também estão vinculados a valores imperativos, mesmo se seus verbos estiverem no presente do indicativo antecedidos de sintagma nominal na terceira pessoa. Em outros termos, esses enunciados expressam valores deônticos oriundos de um indivíduo autorizado e, como verdades universais, não podem ser questionados.

$\mathrm{Na}$ obra de Iacocca e Iacocca (2008), também foram encontrados enunciados destacados. Esses enunciados, de caráter genérico e universalizante, apresentam-se como verdades ou como enunciações soberanas 
para todo o público. Essa natureza de tese evidencia-se no emprego de um tipo específico do tempo verbal presente, relacionado à expressão da atemporalidade dos eventos, processos e estados representados pela predicação.

A respeito do emprego do presente, Fiorin (2001) afirma que este tempo verbal marca a coincidência entre os três momentos básicos que caracterizam a temporalidade linguística: o momento de referência, o momento do acontecimento e o momento da enunciação. $O$ autor ainda elenca os três principais usos deste tempo: o presente pontual, correspondente à enunciação de fatos e eventos que ocorrem simultaneamente ao próprio ato de enunciar; o presente durativo, relacionado à enunciação de hábitos ou de fatos recorrentes e o presente gnômico, em que o momento de referência para o que é enunciado é ilimitado, ou seja, é um uso em que se indica que a validade das afirmações é atemporal ou não restrita a algum tempo histórico específico. Observa-se, portanto, que este último valor do tempo presente é recorrente nos enunciados da obra em análise, especialmente nos enunciados destacados.

Desse modo, a validade das afirmações do enunciador ultrapassa contextos específicos, momentos históricos, ideologias, etc. Embora os conteúdos desses enunciados possam ser questionados, são apresentados como verdades indiscutíveis, diante das quais só cabe a aceitação. A seguir, apresentam-se alguns exemplos desses enunciados:

(13) A lealdade, a sinceridade e a compreensão fazem a verdadeira amizade. (IACOCCA; IACOCCA, 2008, p.17).

(14) Ser um bom cidadão, um cidadão de verdade, é participar da sociedade em que se vive, conhecendo e defendendo os próprios direitos e tendo consciência dos próprios deveres. (IACOCCA; IACOCCA, 2008, p.32).

(15) Fumar é... não preservar a saúde ... desrespeitar as pessoas... poluir o ambiente.[...] (IACOCCA; IACOCCA, 2008, p.41).

(16) Ser ético é saber discernir entre o que é bom e ruim para nós mesmos e para os outros. (IACOCCA; IACOCCA, 2008, p.54).

(17) Praticar esportes é sempre bom para o corpo e para a alma. (IACOCCA; IACOCCA, 2008, p.56). 
(18) Quem começa a ler e descobre tudo o que a leitura proporciona, com certeza não pára mais. Quem adquire esse hábito encontra com mais facilidade soluções e respostas para suas questões pessoais, desenvolve o espírito crítico em relação ao comportamento das pessoas, ao lugar em que vive e aos acontecimentos do mundo... (IACOCCA; IACOCCA, 2008, p.86).

(19) Quem não tem medo de se mostrar exatamente como é, sem exibicionismo e competições, adquire 0 respeito dos outros. (IACOCCA; IACOCCA, 2008, p.120).

(20) Respeitar e cultivar esses valores significa estar sempre atento aos próprios sentimentos e atitudes, possuir mais segurança na hora de agir, sentir-se gente de verdade. (IACOCCA; IACOCCA, 2008, p.138).

Como verificado anteriormente por Brunelli (2011), os enunciados aforizados do discurso de autoajuda não apresentam marcas que os ancoram em um contexto específico que lhes limitaria a validade. Também não apresentam marcas dêiticas ou referências definidas. Em relação aos enunciados aforizados da obra em análise, observa-se que, mesmo que os sintagmas nominais empregados na posição de sujeito da oração sejam expressões definidas, como em (13), eles se referem a entidades com alto grau de abstração e generalidade, sem valor referencial no contexto em que são usados, por isso essa asseveração se valida como uma verdade atemporal, relativa ao uso do tempo presente gnômico. Com esses enunciados, o enunciador enuncia verdades e não opiniões pessoais, ao mesmo tempo em que pode, indiretamente, orientar o comportamento dos adolescentes.

O uso do pronome quem também reflete a não-ancoragem dos enunciados em questão a uma situação específica, com o sujeito com referência dêitica. Ou seja, observa-se também a impessoalidade desses enunciados. Embora no enunciado (16) haja pronome pessoal de primeira pessoa do plural, esse pronome indica uma coletividade, uma sociedade e não os interlocutores específicos da obra. Conclui-se que o grupo de destinatários implicados por esses enunciados pretende-se o mais amplo possível, o que pode sugerir também uma atenuação do valor injuntivo desses enunciados e uma aproximação do público ao enunciador da obra, já que essas verdades não 
valem somente para os jovens, mas para todos.

Contudo, convém ressaltar que, embora Maingueneau (2010) tenha caracterizado o enunciador das aforizações como uma instância de saber em uma relação assimétrica hierarquicamente ao público universal a quem se dirige, por sua autoridade em estabelecer verdades inquestionáveis, a recorrência à enunciação aforizante na obra em análise dilui o caráter doutrinário do discurso de autoajuda e do tom autoritário do enunciador, já que o valor deôntico desses enunciados não é explícito. Assim, ordens e proibições são evitadas e substituídas por enunciados que orientam indiretamente, o que está de acordo com a cenografia instaurada pelo discurso, a dos almanaques juvenis, cujo enfoque é o entretenimento e a informação.

\section{Considerações finais}

Constatou-se, na obra analisada, que os enunciados destacados, especialmente aqueles que se apresentam em um regime enunciativo aforizante, cumprem a função de manifestar os fatos enunciados como verdades inquestionáveis e genéricas, cuja validade ultrapassa contextos históricos e que se dirigem a um público universal. De um modo geral, estes enunciados, tal como caracterizados por Maingueneau (2010) e Brunelli (2011), instauram uma relação assimétrica de saber entre o enunciador, fonte dessas verdades universais, e o público. Entretanto, na obra analisada, considerandose a cenografia por ela instaurada, ou seja, a de almanaque juvenil, em que se intercalam as funções de entretenimento e informação, tais enunciados visam também a atenuar o tom impositivo ou autoritário do discurso que enunciados com valor deôntico poderiam conferir-lhe, tornando o tom discursivo mais informativo, o que convém a uma cenografia em que enunciador e enunciatário estão em uma relação mais próxima do que a cenografia geralmente pressuposta pelos enunciados aforizados.

Assim, tal atenuação do tom impositivo do discurso funciona também pelo fato de que o enunciador, na cenografia instaurada, ao mesmo tempo em 
que deve manifestar um ethos de um homem de conhecimento, sábio e apto a orientar o enunciatário jovem a quem se dirige, deve também atenuar 0 autoritarismo de seu discurso, em função de determinada imagem prévia do público, ou seja, a de um público adolescente que não acata ordens e imposições e que deseja aconselhamentos e orientações, que não está disposto a obedecer irrestritamente a um discurso de um enunciador autoritário. Dessa forma, os enunciados aforizados manifestam-se mais como informações gerais a serem transmitidas ao enunciatário do que verdades a serem impostas, e o enunciador mostra-se como um sujeito sábio e apto a orientar seu público, mas que transmite seu saber sem impor diretamente a seus enunciatários seus aconselhamentos.

\section{Referências}

ASSOCIAÇÃO NACIONAL DAS LIVRARIAS. Venda de livros infanto-juvenis cresce e segmento ganha destaque no país. Disponível em: <http://anl.org.br/web/exibe_noticia.php?id=441>. Acesso em: 27 de jan. 2014.

BAUMAN, Zygmunt. O mal-estar da pós-modernidade. Tradução Mauro Gama e Cláudia M. Gama. Rio de Janeiro: Jorge Zahar Editor, 1998.

BRUNELLI, Anna Flora. O sucesso está em suas mãos: análise do discurso de auto-ajuda. 2004. 149f. Tese (Doutorado em Lingüística) - Instituto de Estudos da Linguagem, Universidade Estadual de Campinas, Campinas, 2004.

. Aforização no discurso de autoajuda. Revista do Gel, São Paulo, v.8, n.1, 2011, p. 125-137.

CHAGAS, Arnaldo Toni Souza das. A ilusão no discurso de auto-ajuda e $o$ sintoma social. Ijuí: Editora UNIJUÍ, 2001.

FIORIN, José Luiz. As astúcias da enunciação: as categorias de pessoa, espaço e tempo. 2. ed. São Paulo: Ática, 2001.

FURLAN, Marília Molina. Cenas de enunciação e ethos discursivo: análise do discurso de autoajuda para adolescentes. 2013. 162f. Dissertação (Mestrado em Estudos Linguísticos) - Instituto de Biociências, Letras e Ciências Exatas, Universidade Estadual Paulista Júlio de Mesquita Filho, São José do Rio Preto, 2013. 
IACOCCA, Liliana; IACOCCA, Michele. O livro do adolescente: discutindo idéias e atitudes com o jovem de hoje. São Paulo: Ática, 2008.

MAINGUENEAU, Dominique. Ethos, cenografia, incorporação. In: AMOSSY, Ruth. (Org.) Imagens de si no discurso: a construção do ethos. São Paulo: Contexto, 2008a, p.69-92.

. A propósito do ethos. In: MOTTA, Ana Raquel; SALGADO, Luciana (Org.). Ethos discursivo. São Paulo: Contexto, 2008b. p.11- 29.

. Cenas da enunciação. Tradução Maria Cecília Pérez de Souza-e-Silva. São Paulo: Parábola, 2008c.

. Aforização: enunciados sem texto? In: . Doze conceitos em Análise do Discurso. Tradução Ana Raquel Motta. São Paulo: Parábola, 2010. p. 9-24.

MARCUSCHI, Luiz Antônio. Produção textual, análise de gêneros e compreensão. São Paulo: Parábola Editorial, 2008.

MARÍN-DÍAZ, Dora Lilia. Autoajuda, educação e práticas de si: genealogia de uma antropotécnica. Belo Horizonte: Autêntica Editora, 2015.

MARTHE, Marcelo. O alto-astral da auto-ajuda. Veja, São Paulo, ed. 1777, 13 set. 2002. Disponível em: <http://www.http://veja.abril.com.br/131102/ p_114.html>. Acesso em: 15 fev. 2014.

RÜDIGER, Francisco. Literatura de auto-ajuda e individualismo. Porto Alegre: Ed. da Universidade do Rio Grande do Sul, 1996.

SOBRAL, Adail Ubirajara. Elementos sobre a formação de gêneros discursivos: a fase parasitária de uma vertente do gênero de autoajuda. 2006. 305f. Tese (Doutorado em Linguística Aplicada e Estudos da Linguagem) - Pontifícia Universidade Católica de São Paulo, São Paulo, 2006. 